\title{
Berry Picking - An Ancient Fraternity
}

By ROSE McLAUGHLIN, Indian Head, Sask.

Lodges do not appeal to me, but long before I could read or write the ancient fraternity of berry pickers had marked me for its own. On fine mornings in early July I trotted up the pasture fence and down the graded roadside, filling my cracked white teacup in the little patches of wild strawberries that were strewn about the prairie in the early days. Destroyed long since by wheels and hooves and the drifting dust of the thirties, wild strawberries are seldom seen outside the parklands nowadays, but memory still recalls that childhood task, tedious and exquisite as petit-point - the perfect berries in the long grass, the warm sun on the back, the criss-cross imprint of dry grass on bare knees, the lonely cries of water birds on a nearby slqugh, and always the flowers, roadside roses, lilies round the hay sloughs, and all the delicate blossoms of early summer, harebells and vetches and daisies, blue beards tongue and white anemones, wreathing the tangled prairie grass.

While the wild strawberry grows rarer and rarer, the utilitarian saskatoon continues to flourish. Of all Saskatchewan wild fruits it is the most typical, embodying in its flavor all the essence of the dry, hot, pungent prairie summer. Here is a real man's berry, growing on eight - and ten-foot bushes in quantities sufficient to fill milk pails and cream cans; and when the picking grows monotonous there are diverting side excursions through jungle-like ravines, with blue sky a mile high over the whole show.

Early in August come the raspberries, and picking them is hard work, for the canes are found among new poplar growth, coming up with thistle and the brier through a crisscross of dead branches. What a marvellous compound of odors rises from a wild raspberry patch - winey tang of the berries, mint-scent of bergamot, and reek of roots, strongly overlaid by the smell of wild poplar, sweet clover, and ripening wheat, and the pollen of a dozen fall flowers.

The grass that cuts through the bluff where we pick is lined with wild sunflower, golden rod, and sow thistle, bright foil for the tall spikes of rosy-lavendar fire weed; while the grassy slope to the west, bronzegold tipped in the afternoon sunlight, is delicately starred with asters and highlighted by the soft, bright purple of the blazing star.

In September berry pickers take their final fling, for choke-cherries hang in glowing clusters even after the first light frosts, when the hillsides blaze with color and the air in poplar glades is amber-bright.

And now, counting the jars in the fruit cabinet and recalling the golden hours that were spent in the berry patch, the thought occurs: Why shouldn't berry-picking be as legitimate a sport as, say fishing? That there is a world of difference between the two is evident from the fact that while the newspapers are filled with fish stories all summer long, we never, ever, see a news picture of a girl proudly posing beside an array of jars filled with wild fruit.

My guess is that berry-pickers get no publicity because their sport can't 